Article

\title{
Study on Frost-Suppression Characteristics of Superhydrophobic Aluminum Surface Heat Exchanger Applied in Air Source Heat Pump
}

\author{
Yaxiu Gu ${ }^{1, * \mathbb{D}}$, Guixiang $\mathrm{He}^{1, *}$, Shuaipeng $\mathrm{Li}^{1}$, Weiqi Ding ${ }^{1}$, Hanlin $\mathrm{Li}^{1}$ and Jiahui Duan ${ }^{2}$ \\ 1 School of Civil Engineering, Chang'an University, Xi'an 710061, China; 2021128082@chd.edu.cn (S.L.); \\ 2020128092@chd.edu.cn (W.D.); 2020128093@chd.edu.cn (H.L.) \\ 2 Guangzhou Traffic Design and Research Institute Co., Ltd., Guangzhou 510000, China; djh09120105@163.com \\ * Correspondence: guyaxiu@chd.edu.cn (Y.G.); 2020128091@chd.edu.cn (G.H.)
}

check for updates

Citation: Gu, Y.; He, G.; Li, S.; Ding,

W.; Li, H.; Duan, J. Study on

Frost-Suppression Characteristics of

Superhydrophobic Aluminum

Surface Heat Exchanger Applied in

Air Source Heat Pump. Sustainability

2022, 14, 1954. https://doi.org/

$10.3390 /$ su14041954

Academic Editor: Adrián

Mota Babiloni

Received: 31 December 2021

Accepted: 3 February 2022

Published: 9 February 2022

Publisher's Note: MDPI stays neutral with regard to jurisdictional claims in published maps and institutional affiliations.

Copyright: (C) 2022 by the authors. Licensee MDPI, Basel, Switzerland. This article is an open access article distributed under the terms and conditions of the Creative Commons Attribution (CC BY) license (https:// creativecommons.org/licenses/by/ $4.0 /)$.

\begin{abstract}
In order to solve the frosting problem of air source heat pump (ASHP) outdoor heat exchange under low-temperature and low-humidity conditions, a superhydrophobic aluminum (Al) surface with a contact angle (CA) of $158.3^{\circ}$ was prepared by chemical etching. The microscopic characteristics of droplet condensation and the freezing process of a superhydrophobic surface were revealed through visual experiments and theoretical analysis. On this basis, the frost-suppression effect of a superhydrophobic Al-based surface simulating the distribution of actual heat exchanger fins was preliminarily explored. The results demonstrated that, due to the large nucleation energy barrier and the coalescence-bounce behavior of droplets, the condensed droplets on the superhydrophobic surface appeared late and their quantity was low. The thermal conductivity of the droplets on a superhydrophobic surface was large, so their freezing rate was low. The frosting amount on the superhydrophobic Al-based surface was $69.79 \%$ of that of the bare Al-based surface. In turn, the time required for melting the frost layer on the superhydrophobic Al-based surface was $64 \%$ of that on the bare Al-based surface. The results of this study lay an experimental and theoretical foundation for the application of superhydrophobic technology on the scale of heat exchangers.
\end{abstract}

Keywords: air source heat pump; superhydrophobic; antifrosting; defrosting; frost-suppression mechanism

\section{Introduction}

Electric ASHPs have found worldwide applications due to their advantages of energy saving and environmental protection [1-3]. However, when the heat pump operates under heating conditions in winter, at ambient air temperatures of $-15^{\circ} \mathrm{C}$ to $11.5^{\circ} \mathrm{C}$ and relative humidity higher than $30 \%$, coil pipes of heat pump outdoor units are prone to frosting [4]. As a result, frost deposition and accumulation on the coil surface will affect the heating capacity, and can even cause the unit to stop in severe cases $[5,6]$.

In order to ensure the operation efficiency of ASHPs in winter, a variety of methods have been proposed to restrain and defrost the frost layer on the coil surface. Commonly used defrosting techniques include electric heating defrosting $[7,8]$, reverse-cycle defrosting $[9,10]$, thermal storage defrosting $[9,10]$, and hot-gas bypass defrosting [10-13]. However, they often need either special equipment or complex process control $[10,14]$. Therefore, finding a stable, high-performance, safe and efficient defrosting technology has become an urgent task. In 1997, Barthlott and Neinhuis [15] established that the unique micro-nano structure of lotus leaves and the presence of a wax film on their surface are the reasons for their antiwetting and superhydrophobic properties. Inspired by the impressive superhydrophobic surfaces in nature, various superhydrophobic materials have been realized for a wide range of antifrost, anticorrosion, antifogging, oil-water separation, and self-cleaning applications [16-19]. Thereinto, the frost resistance of the superhydrophobic 
surface has attracted the attention of many scholars, and numerous surface modification technologies have been proposed to construct superhydrophobic surface structures similar to lotus leaves $[20,21]$. The ASHP defrosting requires that a superhydrophobic surface be constructed on the metal substrate. At present, the commonly used methods for obtaining superhydrophobic surfaces on metal substrates consist of etching [22,23], templating [24,25], anodic oxidation [26], deposition [27,28], and hydrothermal reactions [29].

Superhydrophobic surfaces usually refer to the solid surfaces on which the CA of the droplets is greater than $150^{\circ}$ and the roll-off angle is less than $10^{\circ}$ [30]. The frost-suppression mechanism and the effect of superhydrophobic surface have been deeply investigated by predecessors. In the microscopic observation of frosting process, scholars have found that the frosting process includes droplet formation, droplet freezing, frost crystal formation, and frost layer growth [31]. Huang et al. [32] reported that the water droplet freezing time on the superhydrophobic copper foil surface was later than that on the plain copper foil surface due to the smaller contact area between the spherical water droplets and the superhydrophobic surface. Jung et al. [33] studied the nucleation mechanism theory and heat transfer physics of droplets on superhydrophobic surfaces and established that humidity and flowing gas in the surrounding environment can fundamentally change the crystallization mechanism of ice and greatly affect the ice hydrophobicity of the surface. According to Boreyko et al. [34], the bouncing phenomenon of droplets on the superhydrophobic surface can delay the growth of frost by preventing heterogeneous ice nucleation and limiting the formation of ice bridges between droplets. Luo et al. [35] observed the freezing of droplets on cold surfaces due to ice bridge propagation. In particular, ice bridges were formed between frozen and unfrozen droplets until all droplets on the surface became frozen. Meanwhile, the droplet distribution across the superhydrophobic surface was sparse, and the distances between the frozen and unfrozen droplets were long. In this respect, the droplet freezing speed on the superhydrophobic surface was slower than that on the bare surface. Wang et al. [36] conducted visual frosting experiments on the hydrophilic, hydrophobic and superhydrophobic surfaces, reporting that the superhydrophobic surface showed good frost-inhibition characteristics. Sommers et al. [37] compared the frosting processes on the hydrophilic, bare and hydrophobic surfaces, concluding that the frosting density of the hydrophilic surface was 20-26\% higher than that of the bare surface, whereas the frosting density of the hydrophobic surface was 37-41\% lower than that of the bare surface. Table 1 summarizes the results on superhydrophobic surface frost suppression published in 2010-2021.

In recent years, significant progress has been made in experimental research and theoretical analysis of metal-based superhydrophobic frost-suppression technology, but the study on superhydrophobic technology for ASHP frost suppression is still in the laboratory stage. There are three main reasons. First, a simple, efficient and environmentally friendly preparation technology to produce superhydrophobic metal surfaces on a large scale has not been found yet. Second, the frost-suppression mechanism of the superhydrophobic surface is still poorly understood. Third, the existing data on the superhydrophobic frost suppression are only on the single fin scale, and the application of superhydrophobic layer on the whole surface of the heat exchange requires a thorough investigation. Bearing these circumstances in mind, the preparation of superhydrophobic Al surfaces with longterm stability by means of chemical etching is reported here. Special attention is paid to the frost-suppression mechanism of the superhydrophobic surface in the early frosting stage. The superhydrophobic Al-based surface simulating the distribution of actual heat exchanger fins was prepared, and a visual frost-suppression experiment platform was set up to investigate the frost-suppression effect of superhydrophobic surfaces. The findings of this study open up new prospects for further promotion of superhydrophobic technology for inhibiting frosting of ASHPs. 
Table 1. Studies on superhydrophobic surface frost suppression (2010-2021).

\begin{tabular}{|c|c|c|c|}
\hline No. & Year & Authors & Results \\
\hline 1 & 2010 & Huang [32] & $\begin{array}{l}\text { Due to the smaller contact area between the spherical water droplet and the superhydrophobic } \\
\text { surface, the water droplets' freezing time was later than that on the plain copper foil surface. }\end{array}$ \\
\hline 2 & 2011 & Farhadi [38] & $\begin{array}{l}\text { The superhydrophobic surface had good ice resistance, but the ice resistance of the surface } \\
\text { deteriorated during the icing/deicing cycle. }\end{array}$ \\
\hline 3 & 2012 & Jung [33] & $\begin{array}{l}\text { Humidity and flowing gas in the surrounding environment could fundamentally change the } \\
\text { crystallization mechanism of ice and greatly affect the ice hydrophobicity of the surface. }\end{array}$ \\
\hline 4 & 2013 & Boreyko [34] & $\begin{array}{l}\text { The bouncing phenomenon of superhydrophobic surface droplets could delay the growth of } \\
\text { frost by preventing heterogeneous ice nucleation and limiting the formation of ice bridges } \\
\text { between droplets. }\end{array}$ \\
\hline 5 & 2014 & Liang [31] & $\begin{array}{l}\text { The frosting process included droplet formation, droplet freezing, frost crystal formation, and } \\
\text { frost layer growth. }\end{array}$ \\
\hline 6 & 2015 & Kim [39] & $\begin{array}{l}\text { When the refrigerant temperature was }-10{ }^{\circ} \mathrm{C} \text { or }-12{ }^{\circ} \mathrm{C} \text {, the effect of frost retardation } \\
\text { increased remarkably with an increase in superhydrophobic surface's contact angle. However, } \\
\text { when the refrigerant temperature was }-8^{\circ} \mathrm{C} \text {, the effect of superhydrophobicity diminished at } \\
\text { water contact angles greater than } 150^{\circ} \text {. }\end{array}$ \\
\hline 7 & 2016 & Wang [36] & $\begin{array}{l}\text { Under the same experimental conditions, the frost amount of a superhydrophobic heat } \\
\text { exchanger was reduced by } 18.0 \% \text { and } 38.6 \% \text {, respectively, compared with hydrophilic and } \\
\text { ordinary heat exchangers; the defrosting time was reduced by } 41.7 \% \text { and } 43.2 \% \text {, respectively. }\end{array}$ \\
\hline 8 & 2016 & Sommers [37] & $\begin{array}{l}\text { The frosting density of the hydrophilic surface was } 20-26 \% \text { higher than that of the bare surface, } \\
\text { and the frosting density of the hydrophobic surface was } 37-41 \% \text { lower than that of the bare } \\
\text { surface. }\end{array}$ \\
\hline 9 & 2017 & Ji [40] & $\begin{array}{l}\text { The freezing of droplets on the superhydrophobic took from } 17 \mathrm{~min} \text { to } 26 \mathrm{~min} \text {, while those on } \\
\text { the bare surface froze within } 4 \mathrm{~min} \text {. }\end{array}$ \\
\hline 10 & 2017 & Chu [41] & $\begin{array}{l}\text { Because of the self-propelled movements, the melting droplets on the superhydrophobic } \\
\text { surface became quite dynamic, self-cleaning the surface and leaving very small surface } \\
\text { coverage. }\end{array}$ \\
\hline 11 & 2018 & Kim [42] & $\begin{array}{l}\text { Neither the superhydrophilic surface nor the superhydrophobic one influenced the defrosting } \\
\text { time when the density was less than } 200 \mathrm{~kg} / \mathrm{m}^{3} \text {. However, when the frost layer density was } \\
\text { over } 200 \mathrm{~kg} / \mathrm{m}^{3} \text {, the superhydrophobic surface was effective in reducing defrosting time. }\end{array}$ \\
\hline 12 & 2019 & Luo [35] & $\begin{array}{l}\text { The droplet freezing speed on the superhydrophobic surface was slower than that on the bare } \\
\text { surface due to the ice bridge propagation. }\end{array}$ \\
\hline 13 & 2020 & Wang [43] & $\begin{array}{l}\text { The sprayable superhydrophobic surface showed excellent antifrosting characteristics, and the } \\
\text { frost layer thickness decreased by } 33 \% \text { after frosting for } 60 \mathrm{~min} \text {. }\end{array}$ \\
\hline 14 & 2020 & $\operatorname{Li}[44]$ & $\begin{array}{l}\text { When the surface inclination angle was more than } 30^{\circ} \text {, the drainage rate of the } \\
\text { superhydrophobic surface could reach more than } 90 \% \text {. }\end{array}$ \\
\hline 15 & 2020 & $\mathrm{Li}[45]$ & $\begin{array}{l}\text { Electrochemical measurements revealed that the superhydrophobic surface showed better } \\
\text { corrosion resistance than the bare copper surface and the inhibition efficiency of the } \\
\text { superhydrophobic surface was about } 95.91 \% \text {. }\end{array}$ \\
\hline 16 & 2021 & $\mathrm{Su}[46]$ & $\begin{array}{l}\text { The growth rate of the frost layer on the hydrophilic surface was twice that on the } \\
\text { superhydrophobic surface and three times that on the superhydrophobic surface. }\end{array}$ \\
\hline 17 & 2021 & Reichl [47] & $\begin{array}{l}\text { The frost mass growth rate was reduced between } 16 \% \text { and } 26 \% \text { at the ambient temperature } \\
\text { from }-2.0^{\circ} \mathrm{C} \text { to }+5.5^{\circ} \mathrm{C} \text { for the coated evaporator compared to the mass growth rate of the } \\
\text { uncoated one. }\end{array}$ \\
\hline
\end{tabular}

\section{Materials and Methods}

\subsection{Materials}

Al-based alloy specimens (6.1 wt $\% \mathrm{Zn}, 2.9 \mathrm{wt} \% \mathrm{Mg}, 2.0 \mathrm{wt} \% \mathrm{Cu}, 0.5 \mathrm{wt} \% \mathrm{Fe}, 0.4 \mathrm{wt} \%$ $\mathrm{Si}, 0.3 \mathrm{wt} \% \mathrm{Mn}, 0.28 \mathrm{wt} \% \mathrm{Cr}, 0.2 \mathrm{wt} \% \mathrm{Ti}$, with balance being $\mathrm{Al}$ ) with dimensions of $2.00 \mathrm{~cm}$ $\times 1.00 \mathrm{~cm} \times 0.01 \mathrm{~cm}$, absolute alcohol $(99.7 \%$, AR), hydrochloric acid (37\%, AR), sodium 
hydroxide, hydrofluoric acid (40\%, AR), fluorosilane $\left(\mathrm{C}_{14} \mathrm{H}_{19} \mathrm{~F}_{13} \mathrm{O}_{3} \mathrm{Si}, 97 \%\right.$, $\left.\mathrm{AR}\right)$, acetone $(99.5 \%, A R)$, and deionized (D.I.) water.

\subsection{Fabrication of the Superhydrophobic Surface}

In this paper, superhydrophobic Al surfaces with micro-nano structure were prepared on bare $\mathrm{Al}$ fins by chemical etching. The method employed was as follows. First, the $\mathrm{Al}$ specimens were ultrasonically cleaned with acetone and ethanol baths to remove oil stains on the surfaces. Second, the samples were dipped in $5.0 \mathrm{wt} \% \mathrm{NaOH}$ aqueous solution for $2 \mathrm{~min}$ to remove the oxide layer. Third, the specimens were exposed to etching by immersing them in a mixture of D.I. water, hydrochloric acid, and hydrofluoric acid for $18 \mathrm{~min}$. Fourth, a $30 \mathrm{~min}$ surface modification with fluorosilane was performed. Finally, the specimens were put into an oven at $120^{\circ} \mathrm{C}$ to solidify the fluoride on their surface. To obtain a stable superhydrophobic $\mathrm{Al}$ surface, the last step needed to be repeated three times.

The hydrophobicity of the surface was evaluated by measuring the contact angles (CA) using a contact-angle-measuring instrument (XG-CAM). In order to reduce the error caused by uneven surface etching, the front and back of the specimens were divided into four equal parts, and the average CA value at each centroid was taken as the measurement result of the specimen. In order to reduce the influence of droplet gravity on the measurement results, the droplet volume was limited to $5 \mathrm{~mL}$.

\subsection{Experimental Apparatus}

Figure 1 illustrates the structure of the experimental setup, consisting of a wet air supply and conditioning system, a semiconductor refrigeration installation and a data acquisition device. The wet air supply and conditioning system enables one to adjust the relative humidity of the surrounding air from $43 \%$ to $92 \%$ and the air flow rate from $1.1 \mathrm{~m} / \mathrm{s}$ to $1.3 \mathrm{~m} / \mathrm{s}$, and it is composed of a centrifugal fan and a humidifier. The semiconductor refrigeration system is made up of a circulating water pump, a water tank, a cold light source, a semiconductor refrigeration table and a thin-film temperature transducer, which can provide a variable low-temperature environment from $0{ }^{\circ} \mathrm{C}$ to $-35{ }^{\circ} \mathrm{C}$. The data acquisition system is composed of a charge coupled device camera (CCD), a temperature and humidity data logger and a PC. This system can collect the temperature and humidity data from the experimental platform and record the frosting process on the surface of the experimental specimens. Table 2 summarizes the measuring instruments and their errors.

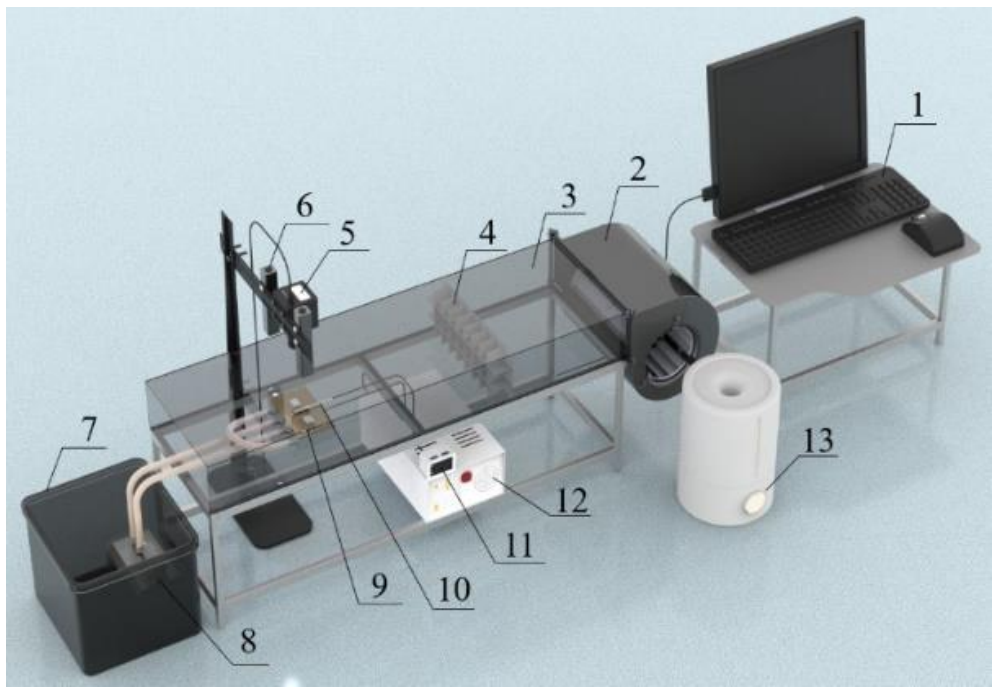

Figure 1. Schematic diagram of the experimental apparatus used in this work. 1. PC. 2. Centrifugal fan. 3. Transparent acrylic air duct. 4. Airflow straightener. 5. Camera. 6. Cold light source. 7. Water tank. 8. Circulating water pump. 9. Semiconductor refrigeration table. 10. Thin-film temperature transducer. 11. Temperature and humidity data logger. 12. Power supply. 13. Humidifier. 
Table 2. Measuring accuracies of measurement instruments.

\begin{tabular}{ccccc}
\hline Equipment & Measure Target & Producer & Model & $\begin{array}{c}\text { Margin of } \\
\text { Error/Precision }\end{array}$ \\
\hline Wind speed recorder & Wind speed & HOBO & WFWZY-1 & $5 \% \pm 0.05 \mathrm{~m} / \mathrm{s}$ \\
\hline $\begin{array}{c}\text { Thin-film } \\
\text { temperature transducer }\end{array}$ & $\begin{array}{c}\text { Temperature of } \\
\text { Al surface }\end{array}$ & TZW & T106 & $\pm 0.1^{\circ} \mathrm{C}$ \\
\hline $\begin{array}{c}\text { Temperature and } \\
\text { humidity data logger }\end{array}$ & $\begin{array}{c}\text { Temperature and RH } \\
\text { of the environment }\end{array}$ & HOBO & MX1101 & $0.21^{\circ} \mathrm{C} \pm 2 \%$ \\
\hline
\end{tabular}

\section{Results and Discussions}

\subsection{Characterization of Superhydrophobic Surface}

In order to clarify the effect of chemical etching on the CA and hydrophobic properties of the surfaces, the bare $\mathrm{Al}$ specimen, the specimen after cleaning, the specimen after oxide layer removal, the specimen after etching and the specimens after surface modification with and without etching were numbered in order of 1-6 (see Table 3). The CA of each specimen was measured and the morphology of droplets on the sample surface was recorded. The data are available in Table 3. In this table, "- " means the step was not carried out; " $\sqrt{ }$ " means the step was carried out.

Table 3. The CA and the morphology of the droplets on each specimen.

\begin{tabular}{ccccccc}
\hline No. & Cleaning & $\begin{array}{c}\text { Removal of } \\
\text { Oxide Layer }\end{array}$ & Etching & Modification & CA & $\begin{array}{c}\text { Droplet } \\
\text { Morphology }\end{array}$ \\
\hline 1 & - & - & - & - & $84.69^{\circ}$ & \\
2 & $\sqrt{ }$ & - & - & - & $85.07^{\circ}$ & \\
3 & $\sqrt{ }$ & $\sqrt{ }$ & - & - & $78.17^{\circ}$ & \\
4 & $\sqrt{ }$ & $\sqrt{ }$ & $\sqrt{ }$ & - & $8.4^{\circ}$ & \\
5 & $\sqrt{ }$ & $\sqrt{ }$ & - & $\sqrt{ }$ & $105.4^{\circ}$ & $\mathbf{\Omega}$ \\
6 & $\sqrt{ }$ & $\sqrt{ }$ & $\sqrt{ }$ & $\sqrt{ }$ & $158.3^{\circ}$ & $\mathbf{\Omega}$ \\
\hline
\end{tabular}

From the measured CA value and the droplet morphology of No. 6, it could be concluded that the chemical etching method used in this study allowed one to successfully prepare a superhydrophobic $\mathrm{Al}$ surface with a $\mathrm{CA}$ of $158.3^{\circ}$. In addition, after cleaning and removing the oxide layer, the $\mathrm{CA}$ of the surface changed little and was still hydrophilic. However, the CA dropped sharply to $8.4^{\circ}$ and showed superhydrophilicity after etching. Compared with No. 5 and No. 6, it was found that the CA of the etched surface was rapidly increased to $158.3^{\circ}$ after modification, while that of the modified surface without etching was $105.4^{\circ}$. This indicated that, even after surface modification, the construction of the micro-nano structure was essential in the preparation of a superhydrophobic surface.

In order to elucidate the reason for why the surface after etching was superhydrophilic, while etching and modification caused the superhydrophobic properties, specimens 4 and 6 were scanned with an electron microscope to observe any changes in their surface microstructure. Figure 2 shows the surface scanning electron microscope (SEM) images of these two specimens. From Figure 2a, a regular stepped structure with a micro-nano size was highlighted on the surface after etching. This stepped structure formed numerous interlaced micro-nano pores. As a result, the droplets in contact with the etched surface penetrated into the pores and spread over the surface of the specimen. This explained why the surface was superhydrophilic after etching. It is also evident from Figure $2 b$ that $a$ layer of a cotton-flocculent low-chemical energy substance uniformly adhered to the step structure of the modified specimen surface. That is because the superhydrophilicity of the specimen surface made the modified solution enter the micro-nano pores of the specimen 
surface after etching. After thermal curing, fluorosilane was retained by the pores, leading to the superhydrophobic property of the surface.

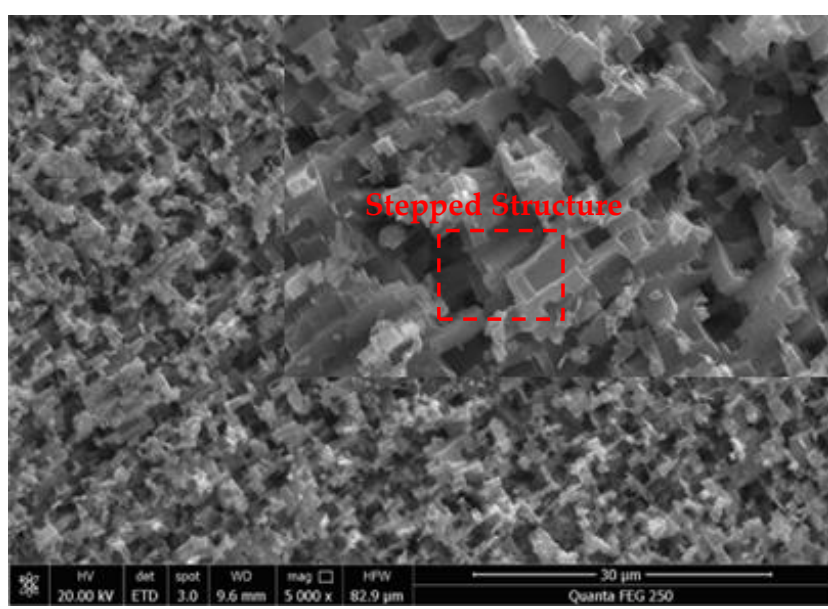

(a)

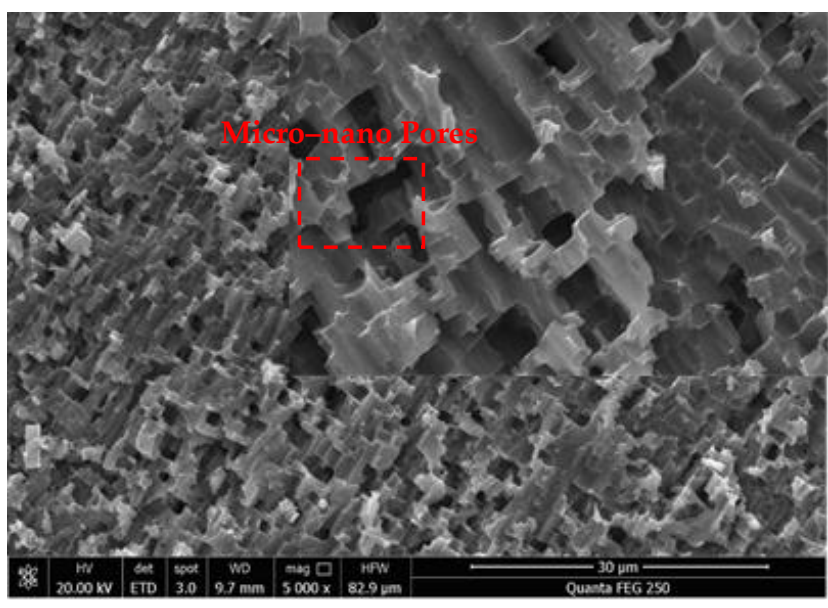

(b)

Figure 2. Surface SEM image of (a) etched and (b) modified specimens.

The EDS mapping of the prepared superhydrophobic specimen was also performed to determine the composition and content of each element in the superhydrophobic material. The results of the full-spectrum analysis are shown in Table 4. In addition, Figure 3 shows the surface composition diagram detected by EDS mapping.

Table 4. Element composition on the surface of a superhydrophobic specimen.

\begin{tabular}{cccc}
\hline Element & $\begin{array}{c}\text { Percentage } \\
\text { by Weight }\end{array}$ & $\begin{array}{c}\text { Percentage by Weight } \\
\text { Sigma }\end{array}$ & $\begin{array}{c}\text { Atomic } \\
\text { Percent Ratio }\end{array}$ \\
\hline C K & 1.87 & 0.0017 & 4.07 \\
O K & 1.09 & 0.0029 & 1.79 \\
F K & 0.07 & 0.0003 & 0.10 \\
Al K & 96.88 & 0.9561 & 93.96 \\
Si K & 0.08 & 0.0003 & 0.08 \\
Overall Amount & 100.00 & - & 100.00 \\
\hline
\end{tabular}

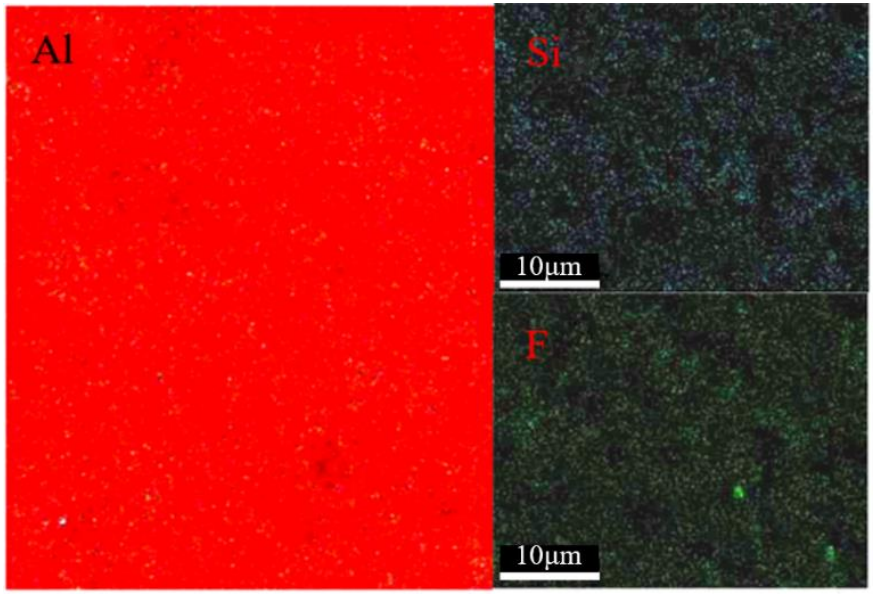

Figure 3. EDS mapping of elements on the superhydrophobic specimen.

Based on Table 3, the prepared superhydrophobic specimen contained only five elements: C, O, F, Al, and Si. Their atomic concentrations changed in descending order 
as follows: $\mathrm{Al}>\mathrm{C}>\mathrm{O}>\mathrm{F}>\mathrm{Si}$, where $\mathrm{C}, \mathrm{O}, \mathrm{F}$, and $\mathrm{Si}$ elements were obtained in the modification solution. According to Figure 3, the homogeneous distribution of $\mathrm{F}$ and $\mathrm{Si}$ on the surface of the specimen indicated that the low-chemical-energy substances were uniformly attached to the surface of the specimen, endowing the Al surface after chemical etching with the superhydrophobic property.

\subsection{Anticondensation Characteristic of the Superhydrophobic Surface}

The condensation process of water vapor in moist air on the cold surface is the basic stage of condensation and frosting. Thus, exploring the condensation characteristic of a superhydrophobic surface would help us to gain insight into the frost-suppression mechanism of the superhydrophobic surface. The condensation experiments of the bare Al surface and the superhydrophobic Al surface were therefore carried out using the experimental platform mentioned in Section 2.3. The relative humidity of the experimental environment was $70 \%$ and the temperature was $11^{\circ} \mathrm{C}$. Figure 4 displays the condensation state of droplets on the two surfaces after $25 \mathrm{~min}$ of exposure to the temperature of $-1{ }^{\circ} \mathrm{C}$. It could be seen from the figure that the condensed droplets spread on the cold bare Al surface, and the size of a single droplet was large, while the contact area between the droplets on the superhydrophobic Al surface was small and the droplets had a spherical shape.

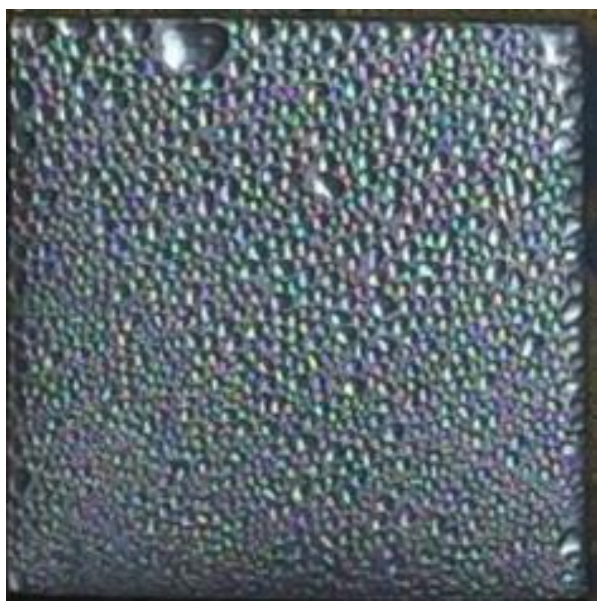

(a)

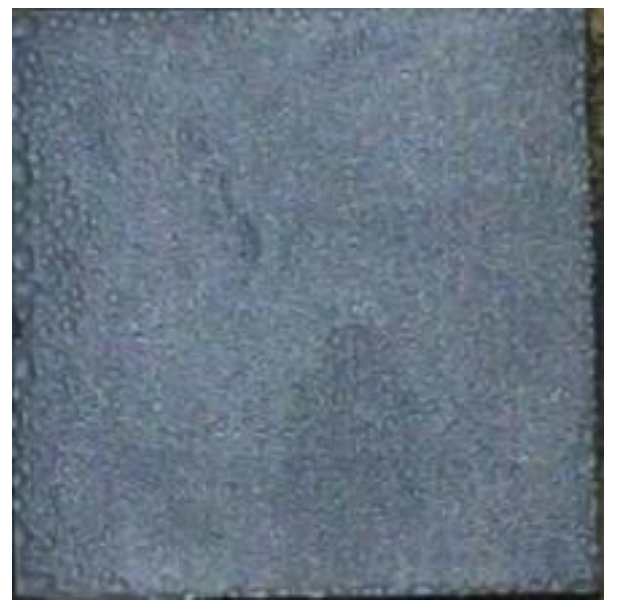

(b)

Figure 4. (a) Condensation of droplets on the bare Al surface at $-1{ }^{\circ} \mathrm{C}$; (b) Condensation of droplets on the superhydrophobic $\mathrm{Al}$ surface at $-1^{\circ} \mathrm{C}$.

In order to make the cold surface undergo droplet condensation without the condensation of moist air, the temperature of the surface should not be too low. In this experiment, the cold surface temperature was adjusted to $0{ }^{\circ} \mathrm{C},-1{ }^{\circ} \mathrm{C},-2{ }^{\circ} \mathrm{C}$ and $-3{ }^{\circ} \mathrm{C}$, to investigate the condensation characteristic of the superhydrophobic surface. The amount of condensed water on the two surfaces was measured every 5 min to obtain the relationship between the amount of condensed water and time at different cold surface temperatures and the result are plotted in Figure 5. 


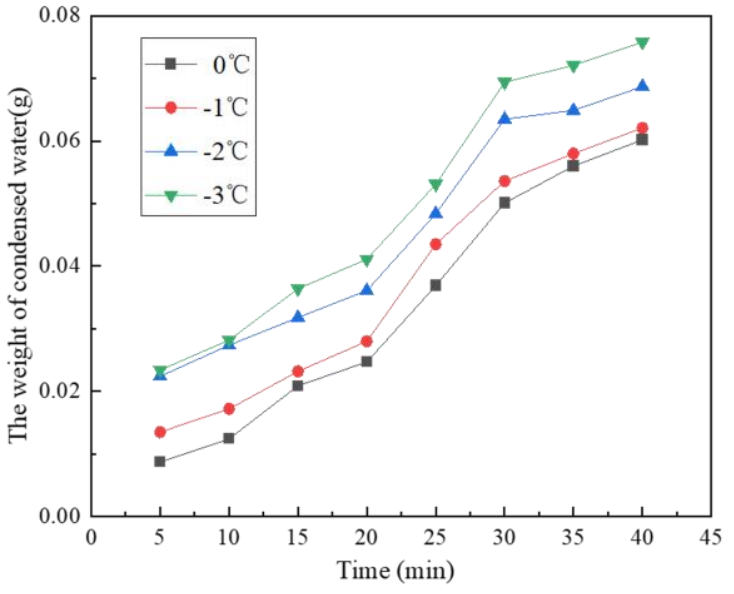

(a)

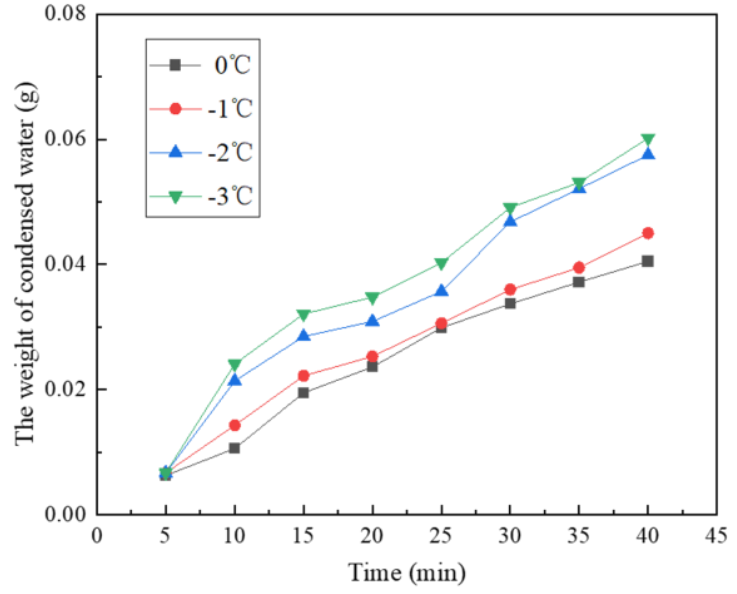

(b)

Figure 5. Weight of droplets at different temperatures (a) on the bare Al surface; (b) on the superhydrophobic Al surface.

The data revealed that the amount of condensed water on both surfaces increased with the decrease in temperature. At any time, the condensation water on the superhydrophobic Al surface was less than that on the bare Al surface at the same temperature. According to linear fitting, the average growth rate of droplet condensation on the bare Al surface was $0.00157 \mathrm{~g} / \mathrm{min}$, while that on the superhydrophobic surface was $0.00119 \mathrm{~g} / \mathrm{min}$. It could be concluded that the superhydrophobic Al surface exhibited better anticondensation properties than the bare Al surface. In addition, as shown in Figure 5, a slag emerged within 20-25 min of the frost growth on the superhydrophobic surface. This was because the anticondensation effect of the superhydrophobic surface in the early frosting stage made the frosting slow during this period.

The anticondensation properties of superhydrophobic surfaces can be explained by the unique condensation nucleation characteristics of droplets.

On the one hand, the droplet has a large nucleation energy barrier on a superhydrophobic surface. According to the theory of phase transformation kinetics, the water vapor in the wet air will agglomerate and droplets will nucleate on the cold surface under a certain degree of undercooling. The surface free energies of liquid-vapor, solid-liquid and solid-vapor are assumed to be $\sigma_{\mathrm{LV}}, \sigma_{\mathrm{SL}}$ and $\sigma_{\mathrm{SV}}$, respectively. The areas of liquid-vapor, solid-liquid and solid-vapor interfaces are referred to as $A_{\mathrm{SV}}, A_{\mathrm{SL}}$ and $A_{\mathrm{LV}}$. In turn, $V$ is the volume and $r$ is the radius of the liquid nucleus.

When liquid nuclei are formed, the Gibbs free energy changes $\Delta G$ are expressed as:

$$
\Delta G=\Delta G_{\mathrm{V}} V+\sigma_{\mathrm{LV}} A_{\mathrm{LV}}+\left(\sigma_{\mathrm{SL}}-\sigma_{\mathrm{SV}}\right) A_{\mathrm{SL}}
$$

The surface free energies of liquid-vapor, solid-liquid and solid-vapor interface have the following relationship with the CA $(\theta)$, which is the so-called Young's equation:

$$
\sigma_{\mathrm{SV}}-\sigma_{\mathrm{SL}}=\sigma_{\mathrm{LV}} \cos \theta
$$

The change of free energy is the largest when the critical liquid core is formed. The critical radius $r_{\mathrm{c}}$ of the liquid core can be found as [35]:

$$
r_{\mathrm{c}}=-\frac{2 \sigma_{\mathrm{LV}}}{\Delta G_{\mathrm{V}}}
$$


The liquid nucleus formed on the plane is a spherical crown. The areas of liquid-vapor, solid-liquid, solid-vapor interfaces and the volume of the liquid nucleus are, respectively:

$$
\begin{gathered}
A_{\mathrm{LV}}=2 \pi r^{2}(1-\cos \theta) \\
A_{\mathrm{SV}}=A_{\mathrm{SL}}=\pi r^{2} \sin ^{2} \theta \\
V=\frac{1}{3} \pi r^{3}\left(2-3 \cos \theta+\cos ^{3} \theta\right)
\end{gathered}
$$

Substituting Formulaes (2)-(6) into Formula (1), the nuclear energy barrier $\Delta G$ on the plane is found to be:

$$
\Delta G=\frac{16 \pi \sigma_{\mathrm{LV}}^{3}}{3 \Delta G_{\mathrm{V}}^{2}}\left(\frac{1}{2}-\frac{3}{4} \cos \theta+\frac{1}{4} \cos ^{3} \theta\right)
$$

Hence, the condensed nuclear barrier reduction factor $f(\theta)$ can be defined as:

$$
f(\theta)=\left(\frac{1}{2}-\frac{3}{4} \cos \theta+\frac{1}{4} \cos ^{3} \theta\right)
$$

The reduction coefficient of condensed nuclear energy barrier $f(\theta)$ represents the induction effect of a solid surface on condensed nucleation. The smaller $f(\theta)$ is, the smaller the condensed nuclear energy barrier is. For a superhydrophobic surface, the value of CA is large and that of $f(\theta)$ is small, so that the condensation nucleation is difficult to form.

On the other hand, the unique coalescence-bounce behavior of droplets caused by the low adhesion of the superhydrophobic surface is also the reason for its anticondensation characteristics. Under the same driving force, condensation nucleation is more likely to occur at the concave surface structure when the size of the condensation liquid nucleus is smaller than or equal to the size of the superhydrophobic surface structure [35]. Moreover, the liquid nucleus formed at the concave surface may form Wenzel droplets after growing up. However, the Wenzel state droplets have high adhesion, which deteriorates the superhydrophobic performance. Therefore, the transformation of Wenzel state droplets into Cassie droplets is the key to maintaining the superhydrophobic performance of the superhydrophobic surface during the condensation process. The adjacent droplets continue to merge with their growth, and the total surface area decreases after the droplet coalescence, thereby leading to a release of some surface energy. The surface adhesion of the superhydrophobic surface is very low, and the energy released by droplet coalescence can overcome the surface adhesion work, which makes the droplet experience the transformation from the Wenzel state into the Cassie state. However, the surface adhesion of the bare Al surface is high, and the surface energy released by droplet coalescence is insufficient to reduce the surface adhesion work. Hence, the merged droplets remain in a Wenzel state. If there is still a residual energy after overcoming the surface adhesion work, it will be transformed into the kinetic energy of the merged droplet. At this time, the droplet can spontaneously bounce off the surface, thus effectively reducing the droplet coverage rate. Figure 6 depicts the coalescence-bounce behavior of droplets on the superhydrophobic surface.

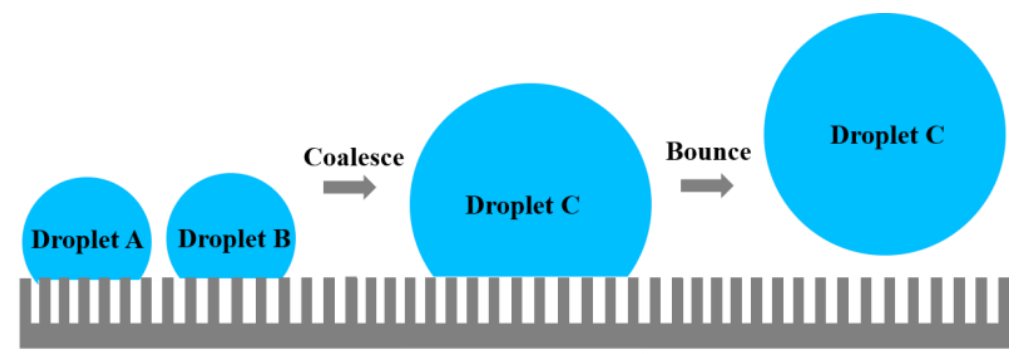

Figure 6. Coalescence-bounce behavior of droplets on the superhydrophobic surface. 


\subsection{Antifreezing Characteristic of the Superhydrophobic Surface}

Frost crystals are always formed first on a frozen droplet, so the moment that the droplet freezes matches the onset of the growth of the frost layer. If the freezing of the droplets is delayed, the start of frost will also be retarded. Therefore, delaying the freezing of the droplets is important for frost suppression. In this work, an experimental study of the freezing process of droplets was performed on the bare and superhydrophobic $\mathrm{Al}$ surface. The relative humidity of the experimental environment was $81 \%$ and the temperature was $22{ }^{\circ} \mathrm{C}$. The cold surface temperature was adjusted to $-5,-8,-11,-14,-17$, and $-20^{\circ} \mathrm{C}$ in turn. In order to make the cold surface undergo droplet condensation without the condensation of moist air, the temperature of the surface should not be too low. In this experiment, the cold surface temperature was adjusted to $0{ }^{\circ} \mathrm{C},-1{ }^{\circ} \mathrm{C},-2{ }^{\circ} \mathrm{C}$ and $-3{ }^{\circ} \mathrm{C}$, to investigate the condensation characteristic of the superhydrophobic surface. In particular, the freezing time of the first droplet on the cold surface was taken as the start freezing time and the freezing time of all droplets on the surface was considered the complete freezing time. Figure 7 depicts the times measured for the two surfaces at different temperatures, enabling one to establish the moments at which droplets started and finished freezing.

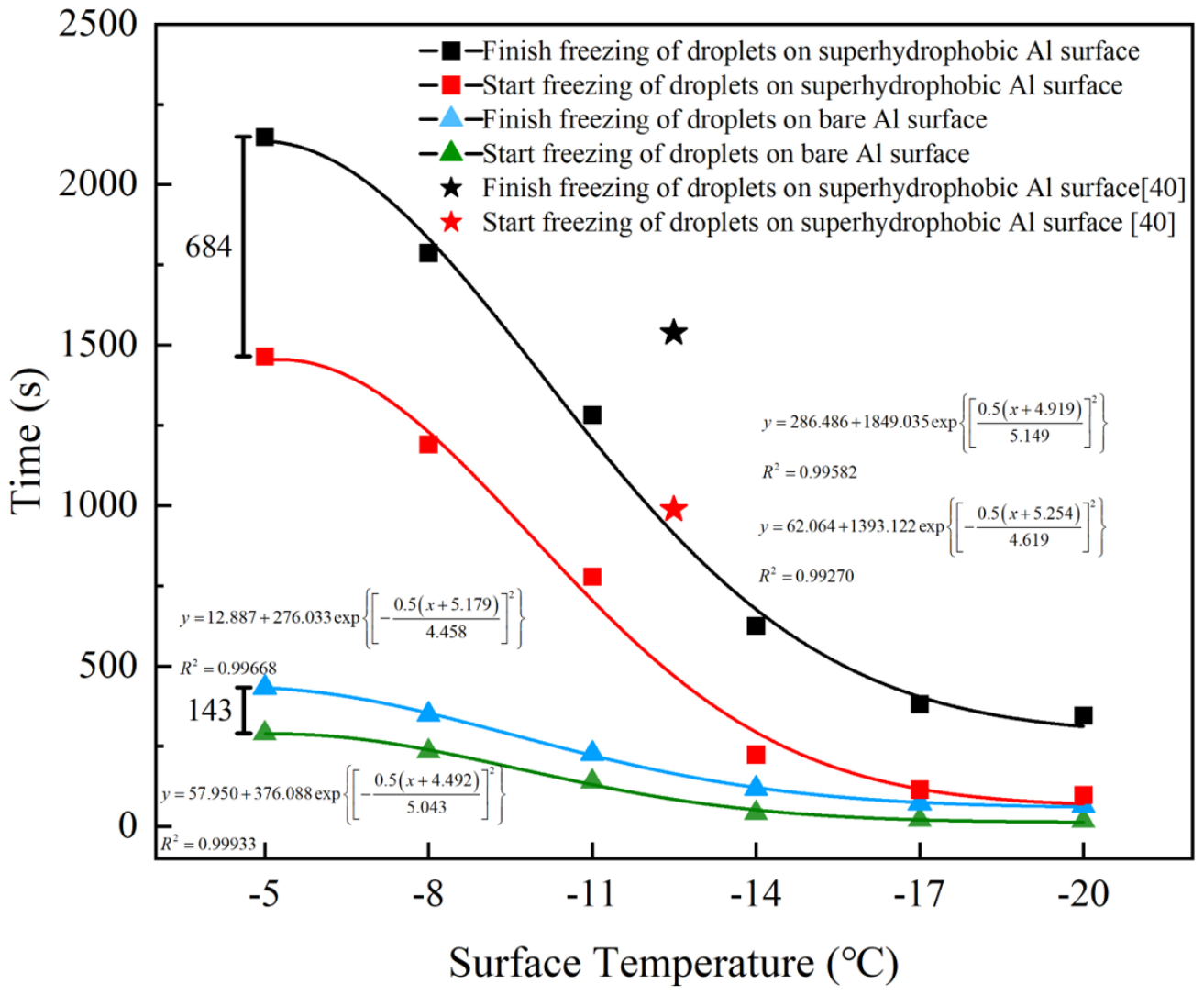

Figure 7. Initial and final freezing times of droplets on the two surfaces at different temperatures.

At $-5{ }^{\circ} \mathrm{C}$, the droplets on the bare $\mathrm{Al}$ surface started to freeze at $290 \mathrm{~s}$ and finished freezing at $433 \mathrm{~s}$. However, the corresponding times on the superhydrophobic $\mathrm{Al}$ surface were $1464 \mathrm{~s}$ and $2148 \mathrm{~s}$. Under this condition, the superhydrophobic Al surface took 5.05 times longer to start frosting than the bare $\mathrm{Al}$ surface and the freezing was 4.78 times slower than on the bare Al surface. As the cold surface temperature decreased, the freezing times for droplets on both surfaces decreased, as did the time required for the entire frosting process. At $-20^{\circ} \mathrm{C}$, the superhydrophobic $\mathrm{Al}$ surface started to freeze in $98 \mathrm{~s}$, which was also $80 \mathrm{~s}$ slower than the bare $\mathrm{Al}$ surface. In general, the average freezing time of droplets on the superhydrophobic $\mathrm{Al}$ surface was 5.19 times longer than on the bare $\mathrm{Al}$ surface at 
various cold surface temperatures. From the results discussed above, one could conclude that superhydrophobic surfaces had good freezing resistance.

The reason for why the superhydrophobic surface exhibits this antifreezing characteristic is that the thermal resistance of droplets on this kind of surfaces is high. Therefore, the next step was to analyze the thermal conductivity during freezing of droplets on the superhydrophobic surface. It is known that the contact surface between the droplet and the superhydrophobic surface is a composite solid-liquid-gas interface and the droplet on the superhydrophobic surface is in Cassie-Baxter state [35]. Figure 8 illustrates the Cassie-Baxter model of a condensed droplet and the schematic diagram of the micro-nano structure of the superhydrophobic surface. The length, width and height of individual papillae of the micro-nano structure are assumed to be $a, a$ and $b$, respectively, and the spacing between adjacent papillae is $c$. The thermal conductivity of air $\lambda_{a}$ is $0.023 \mathrm{~W} /(\mathrm{m} \cdot \mathrm{K})$; the thermal conductivity of $\mathrm{Al} \lambda_{n}$ is $273 \mathrm{~W} /(\mathrm{m} \cdot \mathrm{K})$.

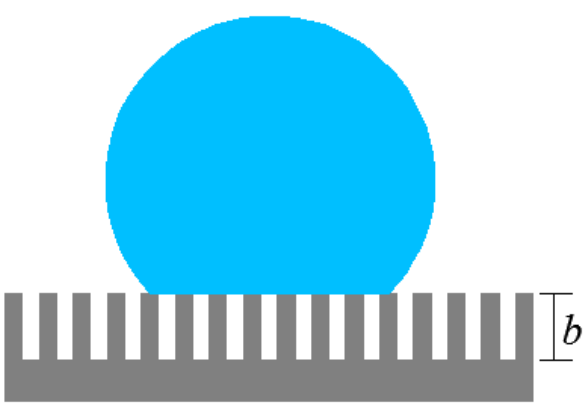

(a)

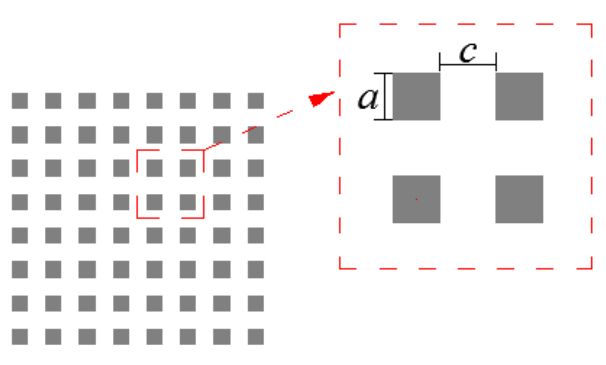

(b)

Figure 8. (a) The Cassie-Baxter model of a condensed droplet; (b) Schematic diagram of a surface micro-nano structure.

The thermal resistance of air conductivity $R_{a}$ is:

$$
R_{a}=\frac{b}{A_{a} \lambda_{a}}
$$

In turn, the thermal resistance of a single papilla structure $R_{n}$ is defined as:

$$
R_{n}=\frac{b}{A_{n} \lambda_{n}}
$$

The relationship between $R_{a}$ and $R_{n}$ gives a parallel thermal resistance, so the total thermal resistance $R_{c}$ of the surface micro-nano structure is:

$$
R_{c}=\frac{1}{\frac{1}{R_{a}}+\frac{1}{R_{n}}}
$$

The ratio of the surface micro-nano structure to the area of the trapped air region is $a^{2}:\left(c^{2}+2 a c\right)$, so that $A_{a}$ and $A_{n}$ can be expressed as:

$$
\begin{aligned}
& A_{a}=\frac{c^{2}+2 a c}{a^{2}+c^{2}+2 a c} \pi r^{2} \sin ^{2} \theta \\
& A_{n}=\frac{a^{2}}{a^{2}+c^{2}+2 \mathrm{ac}} \pi r^{2} \sin ^{2} \theta
\end{aligned}
$$

Substitute Equations (9), (10), (12) and (13) into Equation (11) to obtain the total thermal conductivity thermal resistance: 


$$
R_{c}=\frac{b}{\pi r^{2} \sin ^{2} \theta} \cdot \frac{1}{\lambda_{a}+\left(\lambda_{n}-\lambda_{a}\right)\left(\frac{a}{a+c}\right)^{2}}
$$

In this formula, $\frac{a}{a+c}$ approximately represents the ratio of a solid-liquid contact area to the total contact area of the micro-nano structure. It is assumed that the value of CA of the surface is $160^{\circ}$ and the radius of the droplet on the surface is $0.1 \mathrm{~mm}$. Figure 9 depicts the variation in $R_{c}$ with $\frac{a}{a+c}$ at the heights of the micro-nano structure of $0.1 \mu \mathrm{m}$ and $0.5 \mu \mathrm{m}$.

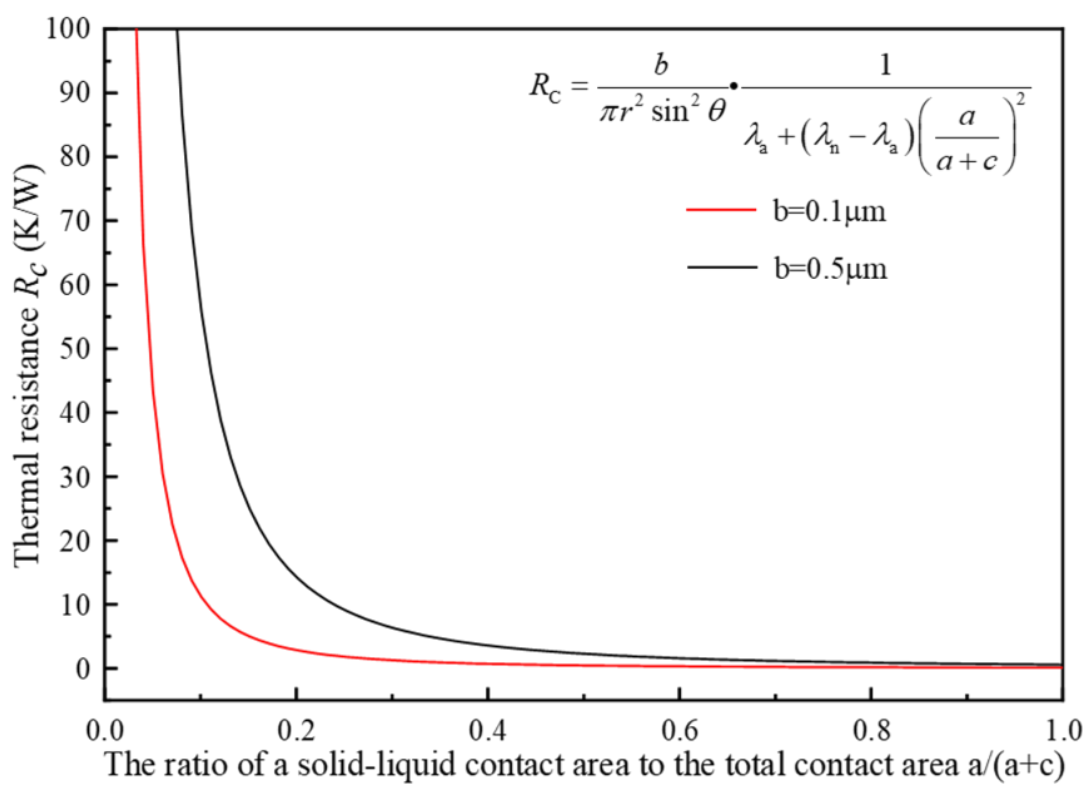

Figure 9. The relationship between the thermal resistance of micro-nano structures on the superhydrophobic surface and the percentage of a solid-liquid contact surface.

The $R_{c}$ value at $b=0.1 \mu \mathrm{m}$ and $\frac{a}{a+c}=0.1$ was found to be $11.57 \mathrm{~K} / \mathrm{W}$, decreasing to $0.17 \mathrm{~K} / \mathrm{W}$ (about 68 times lower) at $b=0.1 \mu \mathrm{m}$ and $\frac{a}{a+c}=0.9$. That was due to the fact that as $\frac{a}{a+c}$ decreased, the trapped air area increased, and the thermal resistance also increased. Therefore, droplet freezing could be effectively inhibited by increasing the area of intercepted air under the Cassie-Baxter wetting plot. On the other hand, the thermal resistance $R_{c}$ increased by about 5.4 times (from 11.57 to $62.17 \mathrm{~K} / \mathrm{W}$ ) when $b$ rose from 0.1 to 0.5 . Thus, it could be concluded that increasing the height of the micro-nano structure at the same percentage of the trapped air area enabled one to also slow down the freezing rate of the droplets.

\subsection{Antifreezing Test of the Superhydrophobic Surface}

To advance the application of superhydrophobic surfaces at the heat exchanger scale, vertical fin bare and superhydrophobic Al bases (hereafter referred to as the bare Al base and the superhydrophobic Al base), both simulating the distribution of actual heat exchanger fins, were afterwards prepared in this work. The shapes of the Al bases are shown in Figure 10. Experimental studies were carried out to elucidate the frost-suppression and melting effects for these bases. During experiments, the ambient temperature was $7^{\circ} \mathrm{C}$ and the relative humidity was $37 \%$. The temperature of the cold surface was adjusted to $-18^{\circ} \mathrm{C}$ in order to create a uniform needlelike layer of frost on each fin, considering that the refrigeration table provided cooling to several fins. The frosting on both surfaces is illustrated in Figure 10, and the change in the weight of the frost layers within $60 \mathrm{~min}$ of frosting is shown in Figure 11. 

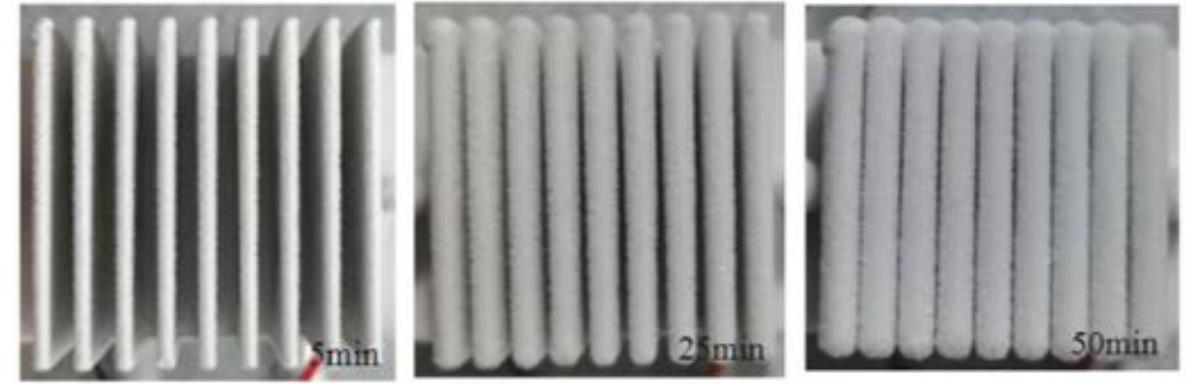

(a)
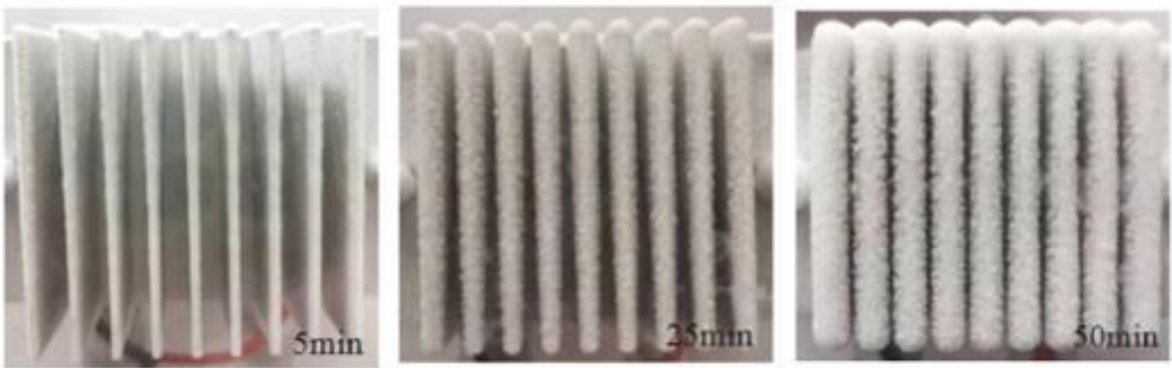

(b)

Figure 10. Frosting process on (a) bare and (b) superhydrophobic Al-based surfaces after 5 min, $25 \mathrm{~min}$ and $50 \mathrm{~min}$.

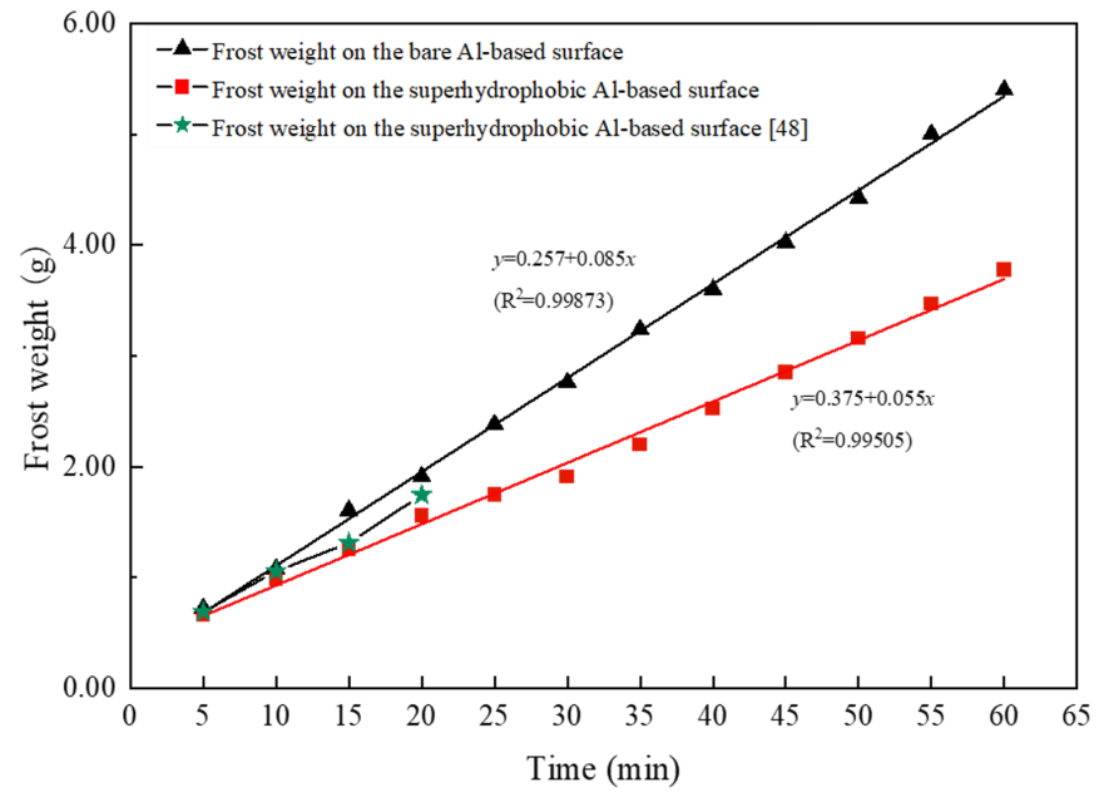

Figure 11. Variation of frost layer weight with time.

As can be seen from Figure 11, frost crystals have been formed on both Al-based surfaces by $5 \mathrm{~min}$ after the start of frosting. The amounts of frosting on the superhydrophobic and bare Al-based surfaces were $0.6588 \mathrm{~g}$ and $0.7218 \mathrm{~g}$, respectively. After $25 \mathrm{~min}$ of frosting, the frost layers entered the full development period and widely appeared on both surfaces. Thus, the weights of frost on the superhydrophobic and bare Al-based surfaces were $1.746 \mathrm{~g}$ and $2.3824 \mathrm{~g}$, respectively. The quantity of frost on the superhydrophobic Al-based surface was only $73.29 \%$ of that on the bare Al-based surface, which indicated that the superhydrophobic surface had an excellent frost-suppression property in the early stage of frosting. By $50 \mathrm{~min}$ of the frosting process, the frost weight on the superhydrophobic Al-based surface was still $71.36 \%$ of that of the bare Al-based surface. According to linear 
fitting, the average growth rate of frost weight was $0.08481 \mathrm{~g} / \mathrm{min}$ for the bare Al-based surface and $0.05529 \mathrm{~g} / \mathrm{min}$ for the superhydrophobic Al-based surface. And the experimental data in this paper are roughly consistent with the experimental data of Jing [48]. One could thereby conclude that the superhydrophobic Al-based surface was endowed with a good frost-suppression effect during the whole frosting process.

After $1 \mathrm{~h}$ of frosting, the refrigeration system and the air supply system were switched off and the frost layers on both Al-based surfaces were allowed to melt in an outdoor environment (temperature of $7^{\circ} \mathrm{C}$, relative humidity of $37 \%$, and wind speed of $1.0 \mathrm{~m} / \mathrm{s}$ ). The melting details of the frost layers on both Al-based surfaces are summarized in Figure 12, including the time taken for the frost layer to melt completely.

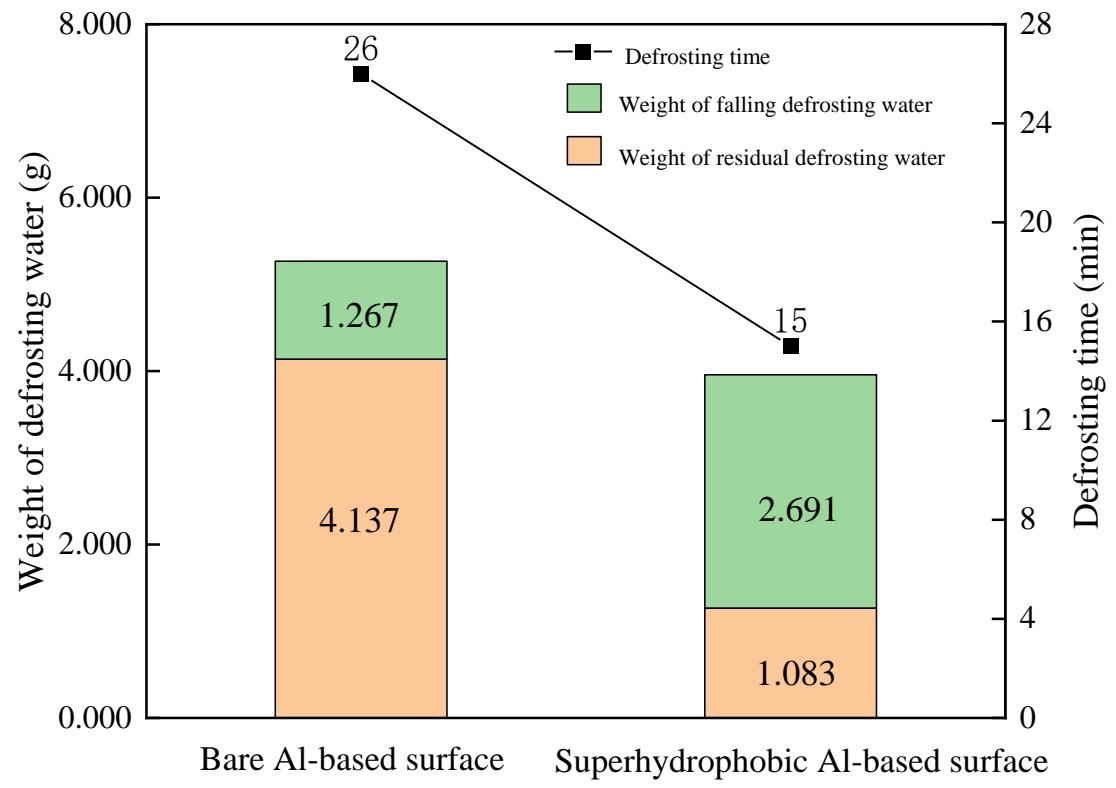

Figure 12. Weight of frost, residence position of defrosting water and defrosting time on two surfaces.

Moreover, liquid films with thicknesses of 1.5 to $4.2 \mathrm{~mm}$ were collected on the bottom of the bare Al-based surface and abundant droplets adhered to the vertical fins after defrosting. However, the superhydrophobic Al-based surface had the little droplet retention. As could be seen from Figure 12, $1.267 \mathrm{~g}$ of defrosted water was dropped from the bare Al-based surface and $4.137 \mathrm{~g}$ of water remained on the surface. In turn, the superhydrophobic Al-based surface lost $2.691 \mathrm{~g}$ of defrost water and retained $1.083 \mathrm{~g}$ of water. In other words, $76.56 \%$ of water remained on the bare Al-based surface after defrosting against $28.70 \%$ on the superhydrophobic Al-based surface. In addition, it took $25 \mathrm{~min}$ for the frost layer to melt completely on the Al-based surface, while the superhydrophobic Al-based surface took $16 \mathrm{~min}$, which was only $64 \%$ of the bare Al-based surface. According to the experimental results, it could be inferred that the application of superhydrophobic technology is promising for reducing the frost melting time and inhibiting secondary frost formation.

\section{Conclusions}

From the technical route of superhydrophobic anti-frost technology, a superhydrophobic Al surface was prepared by chemical etching. A visual experimental platform was built to study the anticondensation and antifreezing properties of this surface, and the experimental results were analyzed by applying the theoretical means. Finally, a superhydrophobic Al-based surface simulating the distribution of actual heat exchanger fins was prepared, and its frost-suppression performance was experimentally studied. Based on the findings of this work, the following conclusions can be drawn: (1) The superhydrophobic Al surface with a CA value of $158.3^{\circ}$ was prepared by chemical etching. In addition, the etching and modification processes were shown to be crucial for the prepa- 
ration of such kinds of surfaces. (2) The anticondensation and antifreezing characteristics of superhydrophobic surfaces were found to be the key reasons for the frost-suppression characteristics of superhydrophobic surfaces. (3) The superhydrophobic Al-based surface was able to inhibit frosting and accelerate defrosting.

The ability to promote the application of superhydrophobic frost-suppression technology was demonstrated with the example of a superhydrophobic heat exchanger. Moreover, the antifrosting effect of superhydrophobic heat exchangers will be within the scope of the forthcoming study. Therefore, the proposed method for the preparation of metal-based superhydrophobic surfaces with a frost-suppression mechanism provides a theoretical and experimental basis for the practical use of superhydrophobic technology in the outdoor heat exchanger surfaces of ASHPs.

Author Contributions: Conceptualization, Y.G.; methodology, Y.G. and J.D.; writing-original draft preparation, G.H., S.L., W.D. and H.L.; writing-review and editing, Y.G.; funding acquisition, Y.G. All authors have read and agreed to the published version of the manuscript.

Funding: This research was supported by the Natural Science Basic Research Program of Shaanxi Province of China, grant number 2018JM5084; Shaanxi Province Housing and Urban Rural Construction Science and Technology Project, grant number 2015-K14; The Fundamental Research Funds for The Central Universities, grant number 300102289203.

Institutional Review Board Statement: Not applicable.

Informed Consent Statement: Not applicable.

Data Availability Statement: All data, models, and code generated or used during the study appear in the submitted article.

Conflicts of Interest: The authors declare no conflict of interest.

\section{Nomenclature}

$\begin{array}{ll}\text { ASHP } & \text { Air source heat pump } \\ \text { Al } & \text { Aluminum } \\ \text { CA } & \text { Contact angle } \\ \text { SEM } & \text { Scanning electron microscope } \\ \Delta G & \text { Gibbs free energy change } \\ \Delta G_{\mathrm{V}} & \text { Gibbs free energy of unit volume liquid nuclues } \\ \sigma_{\mathrm{LV}} & \text { Surface free energy of liquid-vapor } \\ \sigma_{\mathrm{SL}} & \text { Surface free energy of solid-liquid } \\ \sigma_{\mathrm{SV}} & \text { Surface free energy of solid-vapor } \\ A_{\mathrm{SV}} & \text { Area of liquid-vapor } \\ A_{\mathrm{SL}} & \text { Area of solid-liquid } \\ A_{\mathrm{LV}} & \text { Area of solid-vapor } \\ r & \text { Radius of the liquid nucleus } \\ r_{\mathrm{C}} & \text { Critical radius } \\ f(\theta) & \text { Reduction coefficient of condensed nuclear energy barrier } \\ a & \text { Length/ Width of individual papillae of the micro-nano structure } \\ b & \text { Height of individual papillae of the micro-nano structure } \\ c & \text { Spacing between adjacent papillae } \\ \lambda_{a} & \text { Thermal conductivity of air } \\ \lambda_{n} & \text { Thermal conductivity of Al } \\ R_{a} & \text { Thermal resistance of air conductivity } \\ R_{n} & \text { Thermal resistance of a single papilla structure } \\ R_{c} & \text { Total thermal resistance of micro-nano structure } \\ V & \text { Volume of the liquid nucleus } \\ & \end{array}$




\section{References}

1. Zhang, Z.; Wang, R.; Gao, Y.; Liu, H.; Liu, L. Application status and development prospect of heat pump. Refrig. Air-Cond. 2018, $18,1-8$.

2. Liu, Z.; Liu, Y.; He, B.-J.; Xu, W.; Jin, G.; Zhang, X. Application and suitability analysis of the key technologies in nearly zero energy buildings in China. Renew. Sustain. Energy Rev. 2018, 101, 329-345. [CrossRef]

3. Sun, J.; Ma, S.; Huo, C.; Ge, Z.; Zhou, S. Application analysis and prospect of heat pump technology under the goal of carbon neutrality. Water Conserv. Electr. Power Mach. 2021, 43, 22-30.

4. Wang, W.; Zhang, F.; Guo, Q.; Xiao, Q.; Zhao, Y. Investigation of frost status for air source heat pump in different regions of China. J. Hunan Univ. (Nat. Sci.) 2009, 36, 9-13.

5. Song, M.; Deng, S.; Dang, C.; Mao, N.; Wang, Z. Review on improvement for air source heat pump units during frosting and defrosting. Applied Energy 2018, 211, 1150-1170. [CrossRef]

6. Su, W.; Zhang, X. Review of Anti-frosting and Defrosting Methods on Air Source Heat Pump. J. Eng.-Phys. 2021, 42, $2195-2215$.

7. Melo, C.; Knabben, F.T.; Pereira, P.V. An experimental study on defrost heaters applied to frost-free household refrigerators. Appl. Therm. Eng. 2013, 51, 239-245. [CrossRef]

8. Sun, J. Present state and prospect of defrosting method for air source heat pump. Build. Energy Environ. 2017, 36, 42-46.

9. Dong, J.; Deng, S.S.; Jiang, Y.; Xia, L.; Yao, Y. An experimental study on defrosting heat supplies and energy consumptions during a reverse cycle defrost operation for an air source heat pump. Appl. Therm. Eng. 2012, 37, 380-387. [CrossRef]

10. Amer, M.; Wang, C. Review of defrosting methods. Renew. Sustain. Energy Rev. 2017, 73, 53-74. [CrossRef]

11. Lefebvre, D.; Tezel, F.H. A review of energy storage technologies with a focus on adsorption thermal energy storage processes for heating applications. Renew. Sustain. Energy Rev. 2017, 67, 116-125. [CrossRef]

12. Ni, L.; Zhou, C.; Yao, Y.; Jiang, Y. Research progress of air source heat pump heat storage system. J. Refrig. 2017, 38, 23-30.

13. Huang, D.; Li, Q.; Yuan, X. Comparison between hot-gas bypass defrosting and reverse-cycle defrosting methods on an air-towater heat pump. Appl. Energy 2009, 86, 1697-1703. [CrossRef]

14. Zhang, J.; Lan, J.; Du, R.; Gao, G. The performance comparison of several defrosting modes for air-source heat pump. J. Refrig. 2012, 33, 47-49.

15. Neinhuis, C.; Barthlott, W. Characterization and distribution of water-repellent, self-cleaning plant surfaces. Ann. Bot. 1997, 79, 667-677. [CrossRef]

16. Liu, Y.; Li, X.; Yan, Y.; Han, Z.; Ren, L. Anti-icing performance of superhydrophobic aluminum alloy surface and its rebounding mechanism of droplet under super-cold conditions. Surf. Coat. Technol. 2017, 331, 7-14. [CrossRef]

17. Zhang, D.; Li, L.; Wu, Y.; Sun, W.; Wang, J.; Sun, H. One-step method for fabrication of superhydrophobic and superoleophilic surface for water-oil separation. Colloids Surf. Physicochem. Eng. Asp. 2018, 552, 32-38. [CrossRef]

18. Sethi, S.K.; Manik, G. Recent progress in super hydrophobic/hydrophilic self-cleaning surfaces for various industrial applica-tions: A Review. Polym.-Plast. Technol. 2018, 57, 1932-1952. [CrossRef]

19. Wan, Y.; Zhang, M.; Yu, H. Condensation properties of grooved composite microstructured aluminum alloy surface. In Proceedings of the 2019 IEEE International Conference on Manipulation, Manufacturing and Measurement on the Nanoscale (3M-NANO), Zhenjiang, China, 4-8 August 2019; pp. 294-297. [CrossRef]

20. Zhao, M.; Zhou, H.; Kang, W.; Huang, Y.; Zheng, Y. Comparison of methods for fabricating superhydrophobic surface. Acta Mater Compos. Sin. 2021, 38, 361-379.

21. Yan, D.; Liu, Z.; Pan, W.; Zhao, D.; Song, J. Research status on the fabrication and application of multifunctional superhydrophobic surfaces. Surf. Technol. 2021, 50,1-19.

22. Peng, H.; Luo, Z.; Li, L.; Xia, Z.; Du, J.; Zheng, B. Facile fabrication of superhydrophobic Al surfaces by chemical etching and its anti-icing/self-cleaning performances. Mater. Res. Express 2019, 6, 096586. [CrossRef]

23. Kim, J.-H.; Mirzaei, A.; Kim, H.W.; Kim, S.S. Facile fabrication of superhydrophobic surfaces from austenitic stainless steel (AISI 304) by chemical etching. Appl. Surf. Sci. 2018, 439, 598-604. [CrossRef]

24. Ma, X.; Shen, B.; Zhang, L.; Liu, Y.; Zhai, W.; Zheng, W. Porous superhydrophobic polymer/carbon composites for lightweight and self-cleaning EMI shielding application. Compos. Sci. Technol. 2018, 158, 86-93. [CrossRef]

25. Linnea, G.; Ronnie, J.; My, H.; van der Wijngaart, W. Structuring of functional spider silk wires, coatings, and sheets by self-assembly on superhydrophobic pillar surfaces. Adv. Mater. 2018, 30, 1704325. [CrossRef]

26. Nanotechnology-Titanium Dioxide Nanotechnology; Study Findings from China University of Petroleum Broaden Understanding of Titanium Dioxide Nanotechnology (Fabrication and characterization of superhydrophobic $\mathrm{TiO}_{2}$ nanotube coating by a facile anodic oxidation approach). Nanotechnol. Wkly. 2018, 354, 83-91. [CrossRef]

27. Li, S.; Page, K.; Sathasivam, S.; Heale, F.; He, G.; Lu, Y.; Lai, Y.; Chen, G.; Carmalt, C.J.; Parkin, I.P. Efficiently texturing hierarchical superhydrophobic fluoride-free translucent films by AACVD with excellent durability and self-cleaning ability. J. Mater. Chem. A 2018, 6, 17633-17641. [CrossRef]

28. Pi, P.; Hou, K.; Zhou, C.; Li, G.; Wen, X.; Xu, S.; Cheng, J.; Wang, S. Superhydrophobic Cu2S@Cu2O film on copper surface fabricated by a facile chemical bath deposition method and its application in oil-water separation. Appl. Surf. Sci. 2017, 396, 566-573. [CrossRef]

29. Wan, Y.; Chen, M.; Liu, W.; Shen, X.; Min, Y.; Xu, Q. The research on preparation of superhydrophobic surfaces of pure copper by hydrothermal method and its corrosion resistance. Electrochim. Acta 2018, 270, 310-318. [CrossRef] 
30. Gao, X.; Guo, Z. Biomimetic superhydrophobic surfaces with transition metals and their oxides: A review. J. Bionic Eng. 2017, 14, 401-439. [CrossRef]

31. Liang, C.; Wang, F.; Lv, Y.; Fan, C.; Wu, C.; Zhang, X.; Zhang, Y. Experimental study on effect of surface characteristic of fin on frost formation. J. Southeast Univ. (Nat. Sci. Ed.) 2014, 44, 745-750.

32. Huang, L.; Liu, Z.; Liu, Y.; Gou, Y. Preparation and anti-frosting performance of super-hydrophobic surface based on copper foil. Int. J. Therm. Sci. 2011, 50, 432-439. [CrossRef]

33. Jung, S.; Tiwari, M.K.; Doan, N.V.; Poulikakos, D. Mechanism of supercooled droplet freezing on surfaces. Nat. Commun. 2012, 3, 615. [CrossRef] [PubMed]

34. Boreyko, J.B.; Collier, C.P. Delayed Frost Growth on Jumping-Drop Superhydrophobic Surfaces. ACS Nano 2013, 7, 1618-1627. [CrossRef] [PubMed]

35. Luo, Q.; Liang, C. Characteristics of frost spreading during initial stage of condensed droplet freezing on superhydrophobic surface. J. Cent. South Univ. (Sci. Technol.) 2019, 50, 1712-1718.

36. Wang, F.; Liang, C.; Zhang, X.; Zhang, Y. Anti-frosting mechanism and frost melting on superhydrophobic fin surface. J. Enhanc. Heat Transf. 2016, 37, 1066-1070.

37. Sommers, A.D.; Truster, N.L.; Napora, A.C.; Riechman, A.C.; Caraballo, E.J. Densification of frost on hydrophilic and hy-drophobic substrates-Examining the effect of surface wettability. Exp. Fluid Sci. 2016, 75, 25-34. [CrossRef]

38. Farhadi, S.; Farzaneh, M.; Kulinich, S. Anti-icing performance of superhydrophobic surfaces. Appl. Surf. Sci. 2011, 257, 6264-6269. [CrossRef]

39. Kim, D.; Kim, H.; Kim, S.W.; Kim, D.R.; Lee, K.-S. Experimental investigation of frost retardation for superhydrophobic surface using a luminance meter. Int. J. Heat Mass Transf. 2015, 87, 491-496. [CrossRef]

40. Ji, Y.; Zhang, J. Condensation and freezing characteristics of nano-structured superhydrophobic surface in early frosting stage. China Surf. Eng. 2017, 30, 18-25.

41. Chu, F.; Wu, X.; Wang, L. Dynamic Melting of Freezing Droplets on Ultraslippery Superhydrophobic Surfaces. ACS Appl. Mater. Interfaces 2017, 9, 8420-8425. [CrossRef]

42. Kim, H.; Jin, G.; Jeon, J.; Lee, K.-S.; Kim, D.R. Defrosting behavior and performance on vertical plate for surfaces of varying wettability. Int. J. Heat Mass Transf. 2018, 120, 481-489. [CrossRef]

43. Wang, F.; Zhou, Y.; Yang, W.; Ni, M.; Zhang, X.; Liang, C. Anti-frosting performance of sprayable superhydrophobic coating suitable for outdoor coil of air source heat pump. Appl. Therm. Eng. 2020, 169, 114967. [CrossRef]

44. Li, S.; Qian, C.; Li, D.; Zhao, X. Defrosting evolution behavior and drainage characteristic on superhydrophobic surface. J. Refrig. 2020, 41, 48-55.

45. Li, H.; Lu, Y.; Zou, X.; Wang, C.; Wei, H. One Step Preparation of Superhydrophobic Surface on Copper Substrate with An-ti-Corrosion and Anti-Icing Performance. Int. J. Electrochem. Sci. 2020, 11, 10674-10683. [CrossRef]

46. Su, W.; Lu, Z.; Zhang, X. Frost growth dynamics on vertical superhydrophobic fins. CIESC J. 2021, 72, $244-256$.

47. Reichl, C.; Sandström, C.; Hochwallner, F.; Linhardt, F.; Popovac, M.; Emhofer, J. Frosting in heat pump evaporators part A: Experimental investigation. Appl. Eng. 2021, 199, 117487. [CrossRef]

48. Jing, T.; Kim, Y.; Lee, S.; Kim, D.; Kim, J.; Hwang, W. Frosting and defrosting on rigid superhydrohobic surface. Appl. Surf. Sci. 2013, 276, 37-42. [CrossRef] 